\title{
Optogenetic-Mediated Release of Histamine Reveals Distal and Autoregulatory Mechanisms for Controlling Arousal
}

\author{
Rhîannan H. Williams, ${ }^{1 \star}$ Melissa J.S. Chee, ${ }^{2 \star}$ Daniel Kroeger, ${ }^{1}$ Loris L. Ferrari, ${ }^{1}$ Eleftheria Maratos-Flier, ${ }^{2}$ \\ Thomas E. Scammell, ${ }^{1}$ and Elda Arrigoni ${ }^{1}$ \\ ${ }^{1}$ Department of Neurology and ${ }^{2}$ Division of Endocrinology, Beth Israel Deaconess Medical Center, Harvard Medical School, Boston, Massachusetts 02215
}

Histaminergic neurons in the tuberomammillary nucleus (TMN) are an important component of the ascending arousal system and may form part of a "flip-flop switch" hypothesized to regulate sleep and wakefulness. Anatomical studies have shown that the wake-active TMN and sleep-active ventrolateral preoptic nucleus (VLPO) are reciprocally connected, suggesting that each region can inhibit its counterpart when active. In this study, we determined how histamine affects the two branches of this circuit. We selectively expressed channelrhodopsin-2 (ChR2) in TMN neurons and used patch-clamp recordings in mouse brain slices to examine the effects of photoevoked histamine release in the ventrolateral TMN and VLPO. Photostimulation decreased inhibitory GABAergic inputs to the ventrolateral TMN neurons but produced a membrane hyperpolarization and increased inhibitory synaptic input to the VLPO neurons. We found that in VLPO the response to histamine was indirect, most likely via a GABAergic interneuron. Our experiments demonstrate that release of histamine from TMN neurons can disinhibit the TMN and suppresses the activity of sleep-active VLPO neurons to promote TMN neuronal firing. This further supports the sleep-wake "flip-flop switch" hypothesis and a role for histamine in stabilizing the switch to favor wake states.

Key words: electrophysiology; histamine; mouse; optogenetics; TMN; VLPO

\section{Introduction}

Histamine plays a critical role in arousal and in maintaining vigilance. Drugs that block histamine receptor $\mathrm{H} 1$ signaling are often sedating, and mice with disrupted histamine signaling have reduced arousal during the dark period and when placed in a novel environment (Parmentier et al., 2002; Haas et al., 2008; Thakkar, 2011). Although the behavioral effects of histamine on arousal are well established, the specific neural circuits mediating these effects remain elusive.

Neurons of the tuberomammillary nucleus (TMN) produce the histamine-synthesizing enzyme histidine decarboxylase (HDC) and are the only neuronal source of histamine in the CNS (Haas et al., 2008). TMN neurons fire at maximal frequency ( $\leq 10$ $\mathrm{Hz}$ ) during attentive waking, at lower rates during quiet waking, and they become silent during sleep (Takahashi et al., 2006). Correspondingly, CSF histamine levels are highest during wake and lowest during sleep (Mochizuki et al., 1991).

Received Nov. 18, 2013; revised March 10, 2014; accepted March 21, 2014.

Author contributions: R.H.W., M.J.S.C., T.E.S., and E.A. designed research; R.H.W., M.J.S.C., D.K., and L.L.F. performed research; R.H.W. and M.J.S.C. analyzed data; R.H.W., M.J.S.C., E.M.-F., T.E.S., and E.A. wrote the paper.

This work was supported by National Institutes of Health Grant R01NS061863 and Administrative Supplement Utilizing Recovery Act Funds R01NS061863 and P01HL095491. We thank Dr. Matthew R. Palmer for providing software and hardware expertise in these optogenetics studies.

The authors declare no competing financial interests.

${ }^{*}$ R.H.W. and M.J.S.C. contributed equally to this work.

Correspondence should be addressed to Dr. Elda Arrigoni, Department of Neurology, Beth Israel Deaconess Medical Center, Harvard Medical School, 3 Blackfan Circle CLS Room 713 Boston, MA 02215. E-mail: earrigon@bidmc.harvard.edu.

DOI:10.1523/JNEUROSCI.4838-13.2014

Copyright $\odot 2014$ the authors $\quad 0270-6474 / 14 / 346023-07 \$ 15.00 / 0$
TMN neurons project widely throughout the CNS, notably innervating wake-promoting brain regions (Panula et al., 1989), and histamine activates neurons in the locus ceruleus, raphe nuclei, thalamus, basal forebrain, and cortex (Haas et al., 2008). TMN neurons also project heavily to sleep-active ventrolateral preoptic nucleus (VLPO) neurons, which reciprocally innervate the TMN (Sherin et al., 1998; Steininger et al., 2001; Chou et al., 2002). The reciprocal, inhibitory innervation between VLPO and arousal centers, including the TMN underlies the "flip-flop switch" model for sleep and wake transitions (Saper et al., 2010). This mutual inhibition is predicted to stabilize behavioral states while allowing rapid transitions between each state.

This model predicts that the TMN and VLPO inhibit each other through the release of galanin and/or GABA from VLPO neurons, and histamine and/or GABA from TMN neurons, but as yet, there is little experimental support for this mechanism. Additionally, although TMN neurons synthesize GABA, it's unclear whether they release GABA (Kukko-Lukjanov and Panula, 2003; Haas et al., 2008). Therefore, we examined whether TMN neurons inhibit the VLPO by releasing histamine and/or GABA and whether histamine acts on the inhibitory inputs to the TMN, such as those from VLPO. We expressed channelrhodopsin-2 (ChR2) in TMN neurons and examined the electrophysiological responses of TMN and VLPO neurons to photostimulation of TMN somata and afferents.

\section{Materials and Methods}

Animals and stereotaxic viral injections

All mice were treated in accordance with guidelines from the National

Institutes of Health Guide for the Care and Use of Laboratory Animals. All 
A
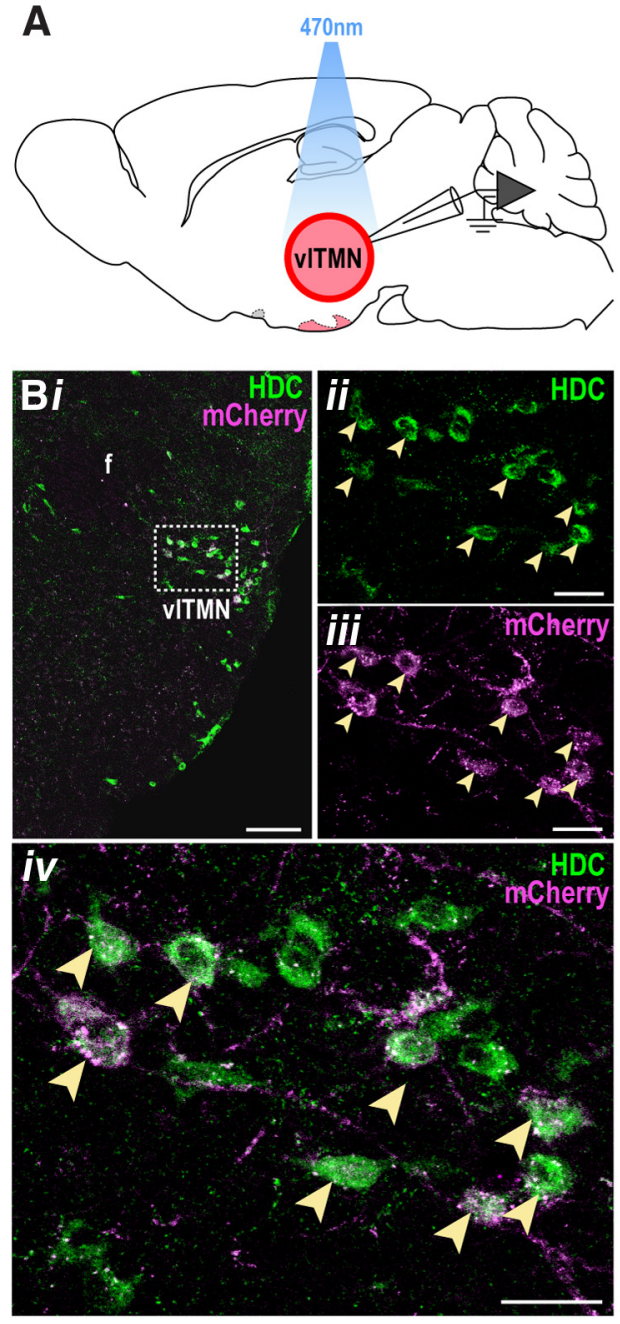

C
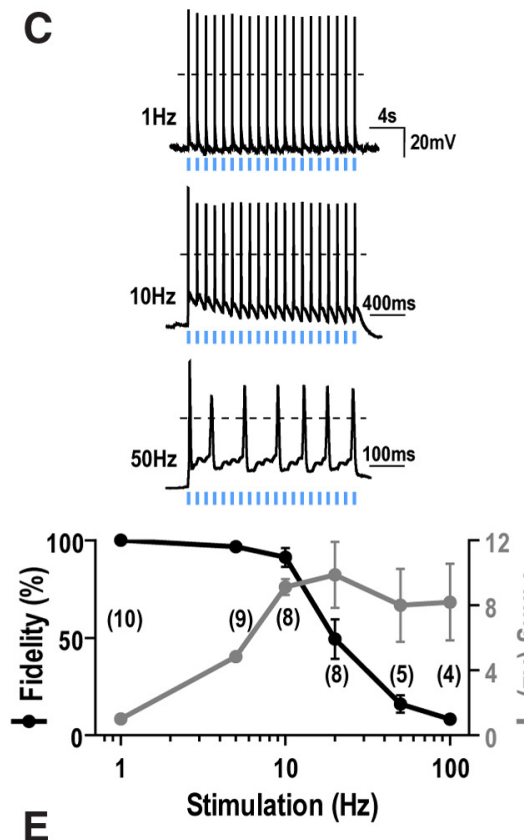

E

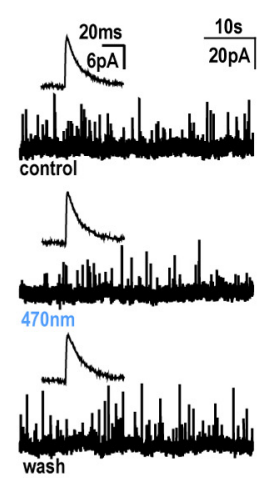

F

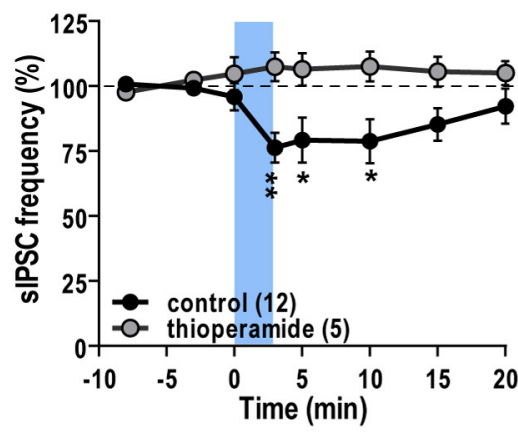

G

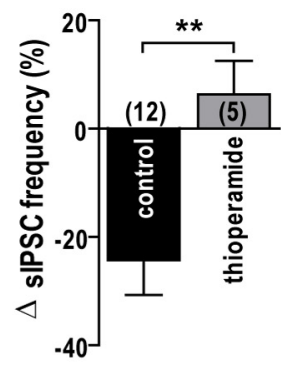

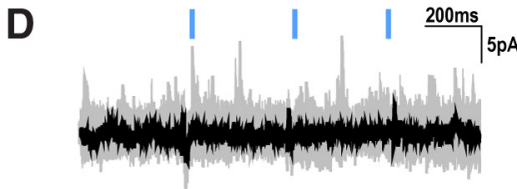
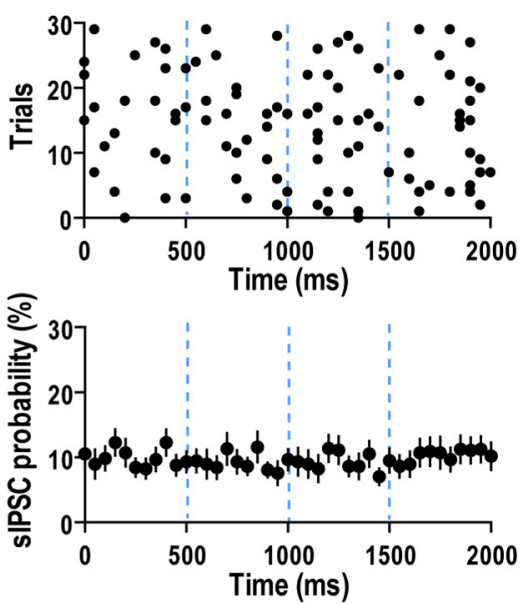

H control
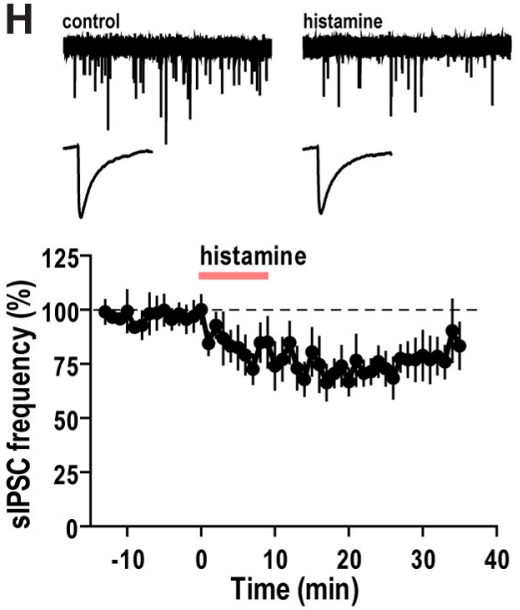
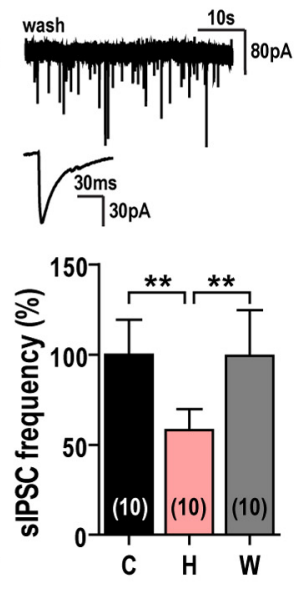

I
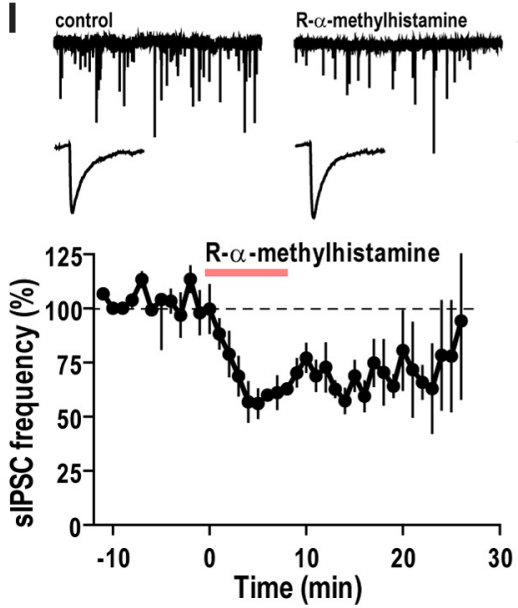
protocols were approved by Beth Israel Deaconess Medical Center Institutional Animal Care and Use Committee. We used age-matched (5 weeks old), male HDC-cre mice (a generous gift from Dr. J.M. Zigman, University of Texas Southwestern) expressing Cre-recombinase under control of the HDC promoter to limit recombination to histaminergic neurons (Yanovsky et al., 2012). As previously described (Mochizuki et al., 2011), we unilaterally microinjected $200 \mathrm{nl}$ of an adeno-associated viral (AAV) vector coding for cre-dependent ChR2 into the ventrolateral TMN (vlTMN) region (anteroposterior $-2.4 \mathrm{~mm}$; mediolateral $0.7 \mathrm{~mm}$; dorsoventral $-4.75 \mathrm{~mm}$ ) (Franklin and Paxinos, 1997). This AAV-FlexChR2(H134R)-mCherry virus (titer: $6 \times 10^{12}$ genomic copies/ml; construct: EF1 $\alpha$-DIO-hChR2(H134R)-mCherry; from Dr. K. Deisseroth, Stanford University) (Chun et al., 2013) was prepared by the University of North Carolina Gene Therapy Center. Three weeks after AAV injections, we performed in vitro optogenetic studies followed by immunohistochemistry.

\section{Electrophysiology}

We prepared coronal brain slices $(250 \mu \mathrm{m})$ in ice-cold, oxygenated ( $95 \%$ $\mathrm{O}_{2}, 5 \% \mathrm{CO}_{2}$ ) sucrose-based ACSF containing the following (in mM): 250 sucrose, $2.5 \mathrm{KCl}, 1.24 \mathrm{NaH}_{2} \mathrm{PO}_{4}, 10 \mathrm{MgCl}_{2}, 10$ glucose, $26 \mathrm{NaHCO}_{3}, 0.5$ $\mathrm{CaCl}_{2}(305 \mathrm{mOsm} / \mathrm{L})$. We then incubated slices in ACSF containing the following (in mM): $124 \mathrm{NaCl}, 2.5 \mathrm{KCl}, 1.24 \mathrm{NaH}_{2} \mathrm{PO}_{4}, 1.3 \mathrm{MgCl}_{2}, 10$ glucose, $26 \mathrm{NaHCO}_{3}, 2.5 \mathrm{CaCl}_{2}(300 \mathrm{mOsm} / \mathrm{L})$ at $37^{\circ} \mathrm{C}$ for $15 \mathrm{~min}$. Thereafter, slices were maintained and recorded at $22^{\circ} \mathrm{C}$.

For current-clamp recordings, the pipette solution contained the following (in mM): $137 \mathrm{~K}$-gluconate, $5 \mathrm{KCl}, 1 \mathrm{MgCl}_{2}, 4 \mathrm{MgATP}, 10$ creatine, $0.4 \mathrm{NaGTP}, 10$ HEPES, 0.1 EGTA (290 mOsm/L, pH 7.25). For voltageclamp recordings, the pipette solution contained the following (in $\mathrm{mM}$ ): 125 Cs-methanesulfonate, $11 \mathrm{KCl}, 10 \mathrm{HEPES}, 0.1 \mathrm{CaCl}_{2}, 1 \mathrm{EGTA}, 5$ MgATP, $0.3 \mathrm{NaGTP}$ (290 mOsm/L, pH 7.25), unless indicated otherwise. All recordings were acquired with a MultiClamp 700B amplifier, Digidata 1440A digitizer interface and pClamp 10 software (Molecular Devices). We monitored changes in input resistance and excluded from analysis any neurons deviating $>10 \%$ over time. We tested antagonist effects only in cells that responded to photostimulation.

We activated ChR2-expressing TMN neurons, axons, and terminals by full-field $470 \mathrm{~nm}$ light pulses (5-10 ms) using a $5 \mathrm{~W}$ Luxeon bluelight-emitting diode (Thorlabs). This light source was coupled to the epifluorescence pathway of Olympus or Zeiss microscopes, producing a 1 -mm-wide beam with $\sim 10 \mathrm{~mW} / \mathrm{mm}^{2}$ power density that has minimal tissue heating effects. This power density is similar to optical fibers implanted for in vivo experiments (Diester et al., 2011).

Recordings and photostimulation of vlTMN neurons. We identified vITMN neurons by their anatomical location and characteristic firing properties (Mochizuki et al., 2011; Williams et al., 2011). When photostimulating the local release of histamine and GABA, we recorded IPSCs in vlTMN neurons at the reversal potential of the ChR2-mediated current $\left(\mathrm{I}_{\mathrm{ChR2}}\right)$ (Atasoy et al., 2012) determined for each cell $\left(\mathrm{V}_{\mathrm{h}}=-5 \mathrm{mV}\right.$ to $-15 \mathrm{mV}$ ). The photostimulation protocol was $10 \mathrm{~ms}$ pulses, 3 pulses in $1.5 \mathrm{~s}$, repeated for 30 trials every $4 \mathrm{~s}$. We tested the effects of histamine and $\mathrm{R}-\alpha$-methylhistamine on spontaneous IPSCs (sIPSCs) at $\mathrm{V}_{\mathrm{h}}=-60 \mathrm{mV}$ in $1 \mathrm{~mm}$ kynurenic acid, with a pipette solution containing the following (in mM): $140 \mathrm{KCl}, 10 \mathrm{HEPES}, 1$ EGTA, $0.3 \mathrm{CaCl}_{2}, 1 \mathrm{MgCl}_{2} \cdot \mathrm{H}_{2} \mathrm{O}, 5$ MgATP, 0.3 NaGTP (290 mOsm/L, pH 7.25).

Recordings from VLPO neurons with photostimulation of histaminergic inputs. We identified VLPO neurons based on their anatomical location and expression of low-threshold spikes (LTSs) (Gallopin et al., 2000;

\footnotetext{
(Figure legend continues.) $\left(\mathrm{V}_{\mathrm{h}}=-5 \mathrm{mV}\right.$ to $\left.-15 \mathrm{mV}\right) . \boldsymbol{H}, \mathbf{I}$, Pharmacological application of histamine or $\mathrm{H} 3$ receptor agonist mimics the effect of photostimulation. Representative current traces (45 s, top) and averaged sIPSCS (200 events; middle) recorded in ACSF (control), $100 \mu \mathrm{M}$ histamine $(H ; \boldsymbol{H})$ or $10 \mu \mathrm{M}$ R- $\alpha$-methylhistamine (Me-H; $\boldsymbol{I})$, and after washout (wash). Time course and mean change in sIPSC frequency (\% baseline; $\left.V_{h}=-60 \mathrm{mV}\right)$ after bath application of histamine $(\boldsymbol{H}$, bottom) or R- $\alpha$-methylhistamine (I, bottom). Photostimulation and drug applications are indicated by blue bars/lines and red bars, respectively. $\boldsymbol{F}, \boldsymbol{H}, \boldsymbol{I},{ }^{*} p<0.05$; ${ }^{* *} p<0.01$ (RM-ANOVA, Bonferroni post hoc test). $G,{ }^{* *} p<0.01$ (unpaired $t$ test).
}

Chamberlin et al., 2003; Liu et al., 2010). For voltage-clamp recordings, we held VLPO neurons at $\mathrm{V}_{\mathrm{h}}=-5 \mathrm{mV}$. The photostimulation protocol was $10 \mathrm{~ms}$ pulses, 3 pulses in $3 \mathrm{~s}$, repeated for 100 trials every $5 \mathrm{~s}$. We included $0.1 \%$ Lucifer yellow in the pipette solution.

\section{Immunohistochemistry}

To produce green fluorescent labeling of histaminergic neurons, we incubated formalin-fixed, coronal TMN sections $(40 \mu \mathrm{M})$ with anti-guinea pig-HDC antibody (1:325, 24 h; American Research Products) followed by biotin-conjugated donkey anti-guinea pig (1:250, 2 h; Jackson ImmunoResearch Laboratories) and streptavidin-conjugated Alexa-488 (1: 1000, $1 \mathrm{~h}$; Invitrogen). We identified neurons expressing ChR2 with native mCherry fluorescence.

\section{Chemicals}

We purchased histamine dihydrochloride, (R)-(-)- $\alpha$-methylhistamine dihydrobromide, mepyramine maleate, and thioperamide from Tocris Bioscience. All other chemicals were from Sigma-Aldrich.

\section{Data and statistical analysis}

We analyzed patch-clamp recording data using Clampfit 10 (Molecular Devices) and synaptic events using MiniAnalysis (Synaptosoft). We used the nonparametric Kolmogorov-Smirnov test (K-S test; MiniAnalysis) to quantify the effects of photostimulation or pharmacological treatments on sIPSC frequency; a neuron was defined as responsive to intervention if $p<0.05$. We generated sample traces with Igor Pro version 6 (WaveMetrics) and graphs with Prism 5 (GraphPad). We represented data as mean \pm SEM; $n=$ number of cells per group (represented in parentheses for figures). We compared group means using unpaired or paired $t$ tests and analyzed changes over time by repeated-measures (RM)-ANOVA followed with Bonferroni post hoc test.

\section{Results}

Microinjection of AAV-Flex-ChR2 into the TMN region of HDC-cre mice produced selective expression of ChR2-mCherry in $25 \pm 11 \%$ of HDC-immunoreactive vlTMN neurons $(n=2$ mice; Fig. 1). Within the vlTMN region, $92 \pm 8 \%$ of mCherryexpressing cells were labeled for HDC, whereas no mCherryexpressing cells were found outside the vlTMN region. In addition, mCherry was strongly expressed in distal TMN axons, including those in the VLPO (Chou et al., 2002).

Optogenetic release of histamine but not GABA in the vlTMN We recorded from ChR2-expressing vlTMN neurons to determine: (1) how light pulses entrain their firing; (2) whether photostimulation releases histamine and/or GABA locally; and (3) how this affects surrounding vlTMN neurons.

At stimulation frequencies $<5 \mathrm{~Hz}$, blue-light pulses (5 ms) evoked single action potentials and entrained vlTMN neurons in a temporally precise manner $(>97 \%)$. Spike fidelity fell substantially at stimulation frequencies $>10 \mathrm{~Hz}(20 \mathrm{~Hz}: 53.5 \pm 11.7 \%$, $n=8 ; 100 \mathrm{~Hz}: 8.8 \pm 2.0 \%, n=4)$, so $10-100 \mathrm{~Hz}$ photostimulation resulted in vlTMN firing rates between 8 and $10 \mathrm{~Hz}$ (Fig. 1C). This suggests that effective coupling between photostimulation and neuronal firing is attainable only up to $10 \mathrm{~Hz}$ and that photostimulation at frequencies $>10 \mathrm{~Hz}$ cannot drive vlTMN firing faster than their physiological limit of $\sim 10 \mathrm{~Hz}$ (Takahashi et al., 2006). This property appears attributable to the large A-current, which has been proposed to progressively limit TMN firing rate when the firing frequency is $>3 \mathrm{~Hz}$ (Jackson and Bean, 2007).

To test the hypothesis that TMN neurons release GABA (Kukko-Lukjanov and Panula, 2003), we recorded IPSCs in vlTMN neurons while photostimulating their soma and local collaterals. In all neurons tested $(n=23)$, single light pulses ( $10 \mathrm{~ms})$ failed to trigger temporally correlated IPSCs. In addition, the probability of IPSCs immediately after a light pulse was un- 
A
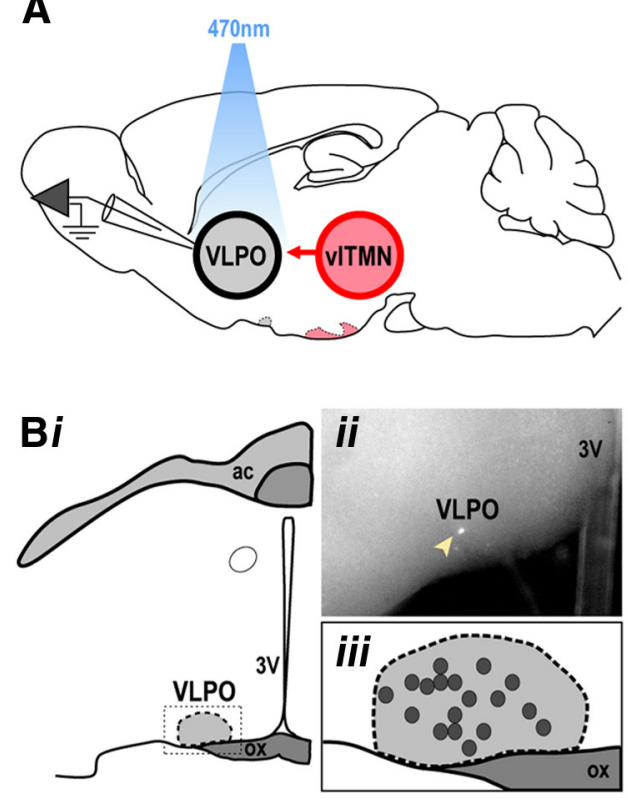

$\mathbf{E}$
C

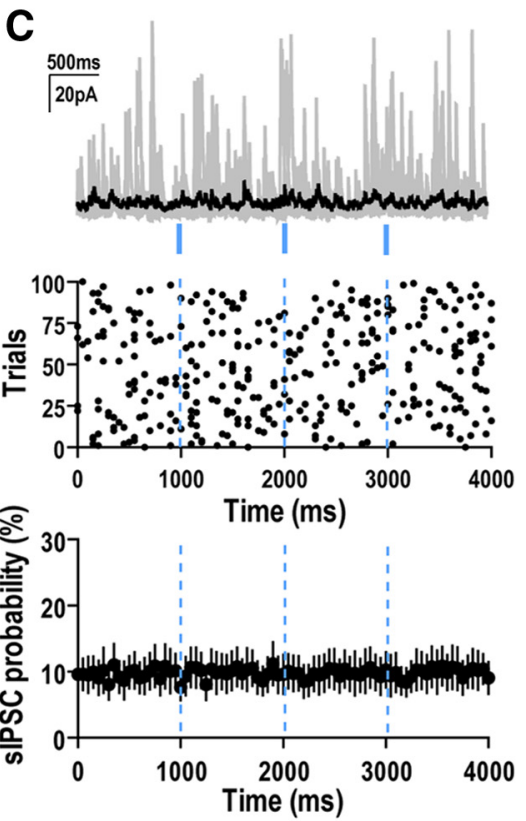

$\mathbf{F}$

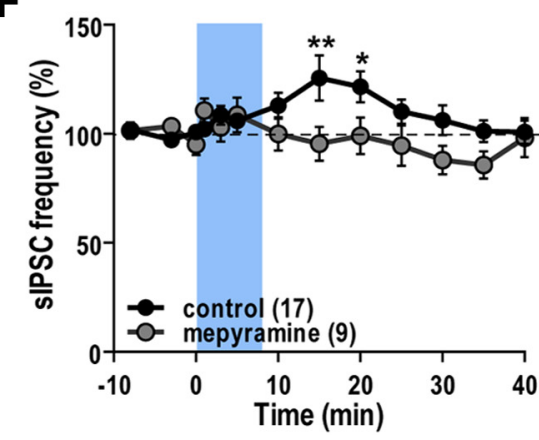

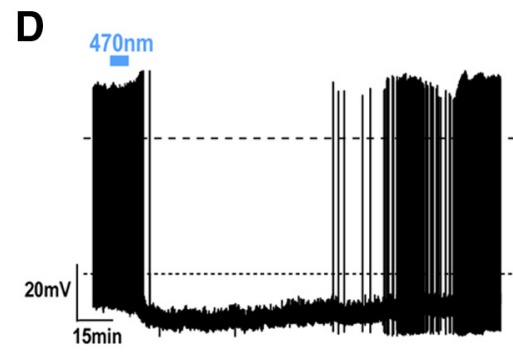

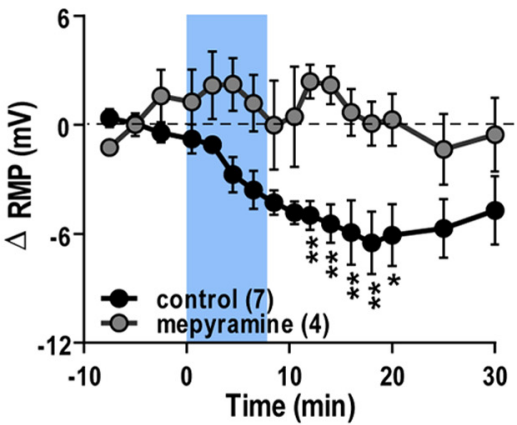

G

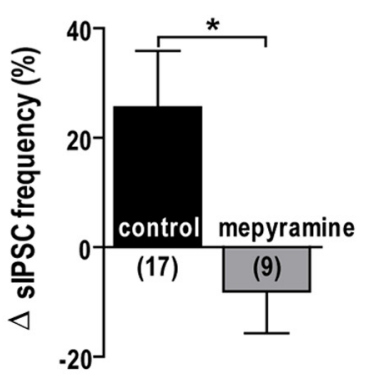

Figure 2. Photostimulation of histaminergic projections increases GABAergic input to VLPO neurons. $A$, Schematic of experimental design. Patch-clamp recordings from VLP0 neurons during photostimulation of ChR2-expressing histaminergic projections with $3 \times 10 \mathrm{~ms}$ light pulses over $3 \mathrm{~s}$, repeated every $5 \mathrm{~s}$ for 100 trials. $\boldsymbol{B}$, Distribution of neurons recorded in the VLPO. Schematic of VLPO-containing brain slice (i); brightfield photomicrograph showing a recorded LuciferYellow-filled cell (arrowhead; scale bar, $200 \mu \mathrm{m}$, ii); distribution of 18 recorded VLP0 neurons (iiii). ac, Anterior commissure; 0x, optic chiasm; 3V, third ventricle. C, Photostimulation of ChR2-expressing TMN axons did not evoke synchronized GABAergic IPSCs in VLPO neurons. Overlay of individual (gray) and averaged current traces (black) with photostimulation $\left(V_{h}=-5 \mathrm{mV}\right.$; top). Raster plot of sIPSC events (middle). No change in VLPO sIPSC probability with each light pulse ( $n=15$; bottom). All show the lack of light-synchronized GABAergic events in VLPO neurons (100 trials, $50 \mathrm{~ms}$ bins). D, Photostimulation of ChR2-expressing histaminergic axons suppressed firing and hyperpolarized VLPO neurons via $\mathrm{H} 1$ receptors. Sample trace of action potential inhibition and resting membrane potential (RMP) hyperpolarization of a VLPO neuron after photostimulation of histaminergic inputs (dashed line, $0 \mathrm{mV}$; dotted line, RMP; top). Mean RMP change of VLPO neurons after photostimulation in control ACSF and $1 \mu \mathrm{m}$ mepyramine (bottom). E-G, Photostimulation of ChR2-expressing TMN axons increased sIPSC frequency in VLPO neurons via H1 receptors. Representative averaged sIPSCs (200 events; left) and current traces (45 s; right) recorded in a VLPO neuron $(\boldsymbol{E})$ in ACSF (control), during $(470 \mathrm{~nm})$, and after photostimulation (wash). Time course of sIPSC frequency change (\% baseline; $\boldsymbol{F})$ and mean difference in sIPSC frequency $(\boldsymbol{G})$ after photostimulation in control and $1 \mu \mathrm{m}$ mepyramine $\left(V_{\mathrm{h}}=-5 \mathrm{mV}\right)$. Photostimulation is indicated by blue bars/dashed lines. $\boldsymbol{D}, \boldsymbol{F},{ }^{*} p<0.05 ;{ }^{* *} p<0.01$ (RM-ANOVA, Bonferroni post hoc test). $\mathbf{G}$, ${ }^{*} p<0.05$ (unpaired $t$ test).

changed (Fig. 1D). These results suggest that GABA is not released from histaminergic collaterals in the vITMN.

We next determined whether repetitive light pulses over $\sim 3$ min could elicit the release of GABA and/or histamine within the vlTMN. As seen with single stimuli, persistent single pulses also did not evoke synchronized GABAergic IPSCs (Fig. 1D, raster plot). This repetitive photostimulation induced a small outward current (3.8 $\pm 1.2 \mathrm{pA}, n=19$; RM-ANOVA, $p=0.007)$ and did not alter resting membrane potential (RMP) in any of the neurons tested $(n=4)$. This suggests that photostimulation does not reliably evoke histamine release or that histamine has little direct effect on vlTMN neurons.

We then examined the effects of vlTMN photostimulation on sIPSCs, as prior work suggested that histamine can inhibit GABAergic inputs to the TMN (Nelson et al., 2002; Zecharia et al., 2009, 2012). In 12 of 20 cells, we found that photostimulation reversibly and significantly reduced sIPSC frequency by $24.3 \pm$ 6.4\%, (K-S test, $0.047>p>0.0001 ; n=12$; RM-ANOVA, $p=$ 0.002 ). The remaining 8 cells were unaffected (K-S test, $0.956>$ $p>0.054)$. In neurons that responded to photostimulation, $1 \mu \mathrm{M}$ thioperamide, an $\mathrm{H} 3$ receptor antagonist, did not alter sIPSC frequency $(8.7 \pm 31.9 \%, n=5)$ but completely blocked the lightevoked reduction in sIPSC frequency (K-S test, $0.696<p<$ $0.062 ;-6.3 \pm 6.2 \%, n=5$; RM-ANOVA, $p=0.014$; unpaired $t$ test control vs thioperamide, $p=0.006$; Fig. $1 E-G)$. This demonstrates that, in the majority of the vlTMN neurons, photostimulation induces histamine release, which reduces GABAergic input to vlTMN neurons through $\mathrm{H} 3$ receptors.

We then compared the effects of light-evoked histamine release to exogenous histamine applications on vlTMN neurons. Similar to the photostimulation response, neither histamine (100 $\mu \mathrm{M}, n=16$ ) nor the $\mathrm{H} 3$ receptor agonist $\mathrm{R}-\alpha$-methylhistamine 


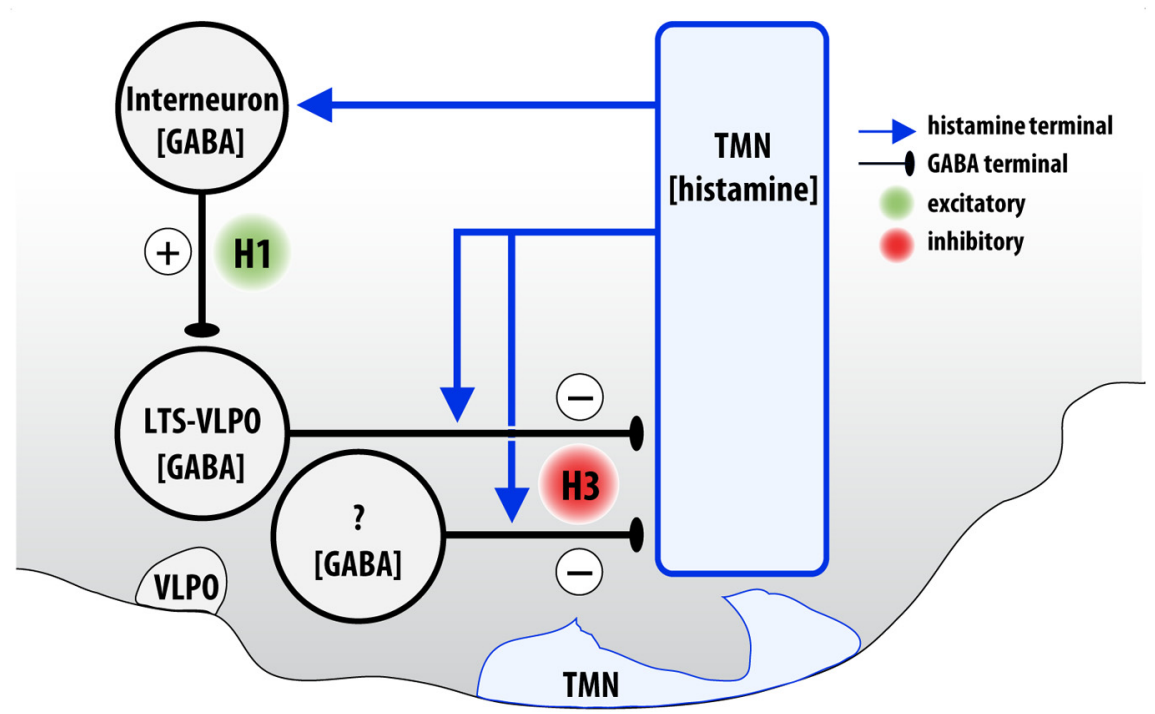

Figure 3. Model of connectivity between wake-active TMN neurons and sleep-active VLPO neurons. During wakefulness, histamine release from TMN neurons acts at $\mathrm{H} 3$ receptors to suppress inhibitory GABAergic inputs, such as those arising from the VLP0. Histamine also acts at $\mathrm{H} 1$ receptors to increase inhibitory output from GABAergic interneurons to the VLP0, thereby producing a feedforward inhibition of VLPO neurons. During sleep, when TMN neurons are inactive, VLPO neurons are disinhibited and can inhibit the TMN.

(10 $\mu \mathrm{M}, n=6)$ altered the membrane currents of vlTMN neurons, but both reduced sIPSC frequency. Specifically, in 10 vITMN neurons, histamine significantly reduced the sIPSC frequency by $35.3 \pm 12.2 \%$ (K-S test, $0.048>p>0.0001 ; n=10$; RM-ANOVA, $p=0.001$; Fig. $1 H$ ). The remaining 6 neurons tested did not respond to histamine (K-S test, $0.854>p>0.104)$. $\mathrm{R}-\alpha$-methylhistamine significantly reduced sIPSCs frequency by $45.7 \pm 15.9 \%$ (K-S test, $0.026>p>0.0001 ; n=4$; RM-ANOVA, $p=0.026$; Fig. $1 I)$. The remaining 2 neurons tested did not respond to R- $\alpha$-methylhistamine (K-S test, $0.167>p>0.132$ ). Together, these optogenetic and pharmacological findings demonstrate that local histamine release suppresses GABAergic inputs to the vlTMN via $\mathrm{H} 3$ receptors.

\section{Optogenetic release of histamine in the VLPO}

Sleep-active neurons of the VLPO are a major input to the TMN (Sherin et al., 1998; Steininger et al., 2001), but it remains unknown whether the TMN affects VLPO activity. We tested whether photostimulation of TMN fibers in the preoptic area affects VLPO neuronal activity (Fig. 2). First, we examined whether GABA was released from TMN axons in the VLPO. Of 17 VLPO neurons examined, photostimulation of histaminergic TMN axons/terminals with single $10 \mathrm{~ms}$ light pulses failed to trigger synchronized IPSCs (Fig. 2C). This suggests that there is no direct release of GABA from histaminergic projections to the VLPO.

Repeated photostimulation of TMN axons hyperpolarized $(-6.5 \pm 1.7 \mathrm{mV}, n=7, \mathrm{RM}-\mathrm{ANOVA}, p=0.009)$ and completely suppressed action potentials in VLPO neurons (Fig. 2D). These cells displayed a prominent LTS with no delayed firing after depolarization, consistent with the electrophysiological properties of VLPO neurons (Gallopin et al., 2000; Chamberlin et al., 2003). Additionally, the effects of photostimulation were abolished by the $\mathrm{H} 1$ receptor antagonist mepyramine $(1 \mu \mathrm{M} ; 0.1 \pm 1.2 \mathrm{mV}$, $n=4$; RM-ANOVA, $p=0.006$; unpaired $t$ test control vs mepyramine, $p=0.034$; Fig. $2 D)$.

Photostimulation of TMN axons also increased the frequency of asynchronous GABAergic sIPSCs by $25.5 \pm 10.4 \%$ in 17 of 23
VLPO neurons (K-S test, $0.046>p>$ $0.0001 ; n=17$, RM-ANOVA, $p=0.015)$. The remaining 6 cells were unaffected (K-S test, $0.983>p>0.079$ ). In neurons that responded to photostimulation, $1 \mu \mathrm{M}$ mepyramine completely blocked the light-evoked facilitation of sIPSC (K-S test, $0.789<p<0.058 ;-8.0 \pm 7.7 \%, n=$ 9; RM-ANOVA, $p=0.0001$; unpaired $t$ test control vs mepyramine, $p=0.020$; Fig. $2 E-G$ ). These data suggest that histamine acts via $\mathrm{H} 1$ receptors to increase the activity of GABAergic neurons that inhibit LTS-type VLPO cells.

\section{Discussion}

Histamine is important for arousal, but the underlying neural circuitry and mechanisms mediating its actions are unclear. In vitro studies have examined the effects of exogenous histamine application, but this is fundamentally limited as bath application likely activates all available receptors in the slice and cannot distinguish responses from histaminergic afferents. Therefore, we used optogenetics to control histaminergic cells and evoke release of histamine in the TMN and VLPO, critical brain regions in the regulation of arousal and sleep, respectively. We demonstrated the release of histamine by photostimulation that suppresses inhibitory GABAergic input to vlTMN neurons. In contrast, release of histamine in the preoptic area produces a feedforward inhibition of VLPO neurons. These findings demonstrate synergistic mechanisms through which histamine may promote arousal by disinhibiting wake-promoting TMN neurons and indirectly inhibiting sleep-promoting VLPO neurons.

Optogenetic release of histamine affected most, but not all, vlTMN and VLPO neurons tested. This was expected as not all HDC-containing vlTMN neurons were transfected with ChR2 (Fig. 1B). In addition, the percentage of vlTMN neurons responding to light-evoked histamine release was similar to the percentage responding to exogenous histamine or $\mathrm{R}-\alpha$ methylhistamine. This suggests heterogeneous expression of $\mathrm{H} 3$ receptors in the vlTMN. Likewise, $\mathrm{H} 1$ receptors may be expressed by only some GABAergic interneurons that synapse onto LTS-VLPO neurons.

It has been speculated that, in addition to histamine, TMN neurons also release GABA, but direct evidence of GABA release is still lacking (Kukko-Lukjanov and Panula, 2003; Haas et al., 2008). TMN neurons contain the GABA-synthesizing enzyme GAD67 (Chotard et al., 2002) and contain small granular deposits of GABA immunoreactivity that are distinct from those containing histamine. This suggested that GABA and histamine are released differently (Kukko-Lukjanov and Panula, 2003). In addition, histaminergic neurons also contain vesicular monoamine transporter-2 (vMAT2) (Merickel and Edwards, 1995), which can package GABA into synaptic vesicles (Tritsch et al., 2012). However, vMAT2 in TMN neurons colocalizes with histamine but not GABA deposits, so it is an unlikely vesicular transporter for GABA (Kukko-Lukjanov and Panula, 2003). We found that photostimulation evoked histamine release in the vlTMN and VLPO, but we were surprised to find no evidence of GABA re- 
lease. This suggests that GABA is probably not released from TMN neurons, although this should be substantiated in other TMN target regions.

Within the vlTMN, photo-evoked histamine release suppressed GABAergic input to TMN neurons via $\mathrm{H} 3$ receptors. As autoreceptors, $\mathrm{H} 3$ receptors are constitutively active and limit the synthesis and release of histamine (Haas and Panula, 2003). As presynaptic heteroreceptors, $\mathrm{H} 3$ receptors inhibit the release of various wake-related transmitters, including noradrenaline, serotonin, and acetylcholine (Brown et al., 2001). Hence, H3 receptors are well suited to regulate sleep-wake behavior (Lin et al., 2011). Our results indicate that most vlTMN cells have little, if any, direct response to optogenetically released histamine, suggesting only a minor role for $\mathrm{H} 3$ autoreceptors on TMN firing. Instead, histamine predominantly acts via presynaptic $\mathrm{H} 3$ receptors to inhibit GABAergic input to vlTMN. Because GABA is not released from vlTMN collaterals, the inhibitory effect of histamine is probably mediated by $\mathrm{H} 3$ heteroreceptors located on nonhistaminergic GABA neurons. The source of this GABA input remains unknown, but some could arise from the VLPO, which is a major source of inhibitory input to the TMN (Sherin et al., 1998) (Fig. 3).

In the VLPO, sleep-promoting cells are identified by their coexpression of GABA and galanin, LTS firing, and norepinephrine sensitivity (Gallopin et al., 2000; Chamberlin et al., 2003; Liu et al., 2010). We found that photostimulated histamine release inhibited LTS-VLPO neurons by $\mathrm{H} 1$ receptor activation that increased GABAergic input to the VLPO neurons. This is consistent with clinical and pharmacological studies demonstrating the importance of $\mathrm{H} 1$ receptors in mediating arousal effects (Nicholson et al., 1985; Brown et al., 2001). Moreover, these data support the hypothesis put forth by Liu et al. (2010) that histamine indirectly inhibits LTS-VLPO cells via GABAergic interneurons expressing $\mathrm{H} 1 / \mathrm{H} 2$ receptors (Fig. 3). This fits well with previous observations that histamine application to the VLPO region increases wakefulness through $\mathrm{H} 1$ receptors (Liu et al., 2010) and that knock-out of $\mathrm{H} 1$ receptors reduces the ability of histamine to promote arousal (Huang et al., 2001).

According to the "flip-flop" hypothesis of sleep and wake regulation, the VLPO and arousal-promoting regions, including the TMN, reciprocally inhibit each other so that activity on one side inhibits the other side, resulting in high activity on either the sleep- or wake-promoting arms of the circuit (Saper et al., 2010). Therefore, GABAergic and galaninergic inhibition from sleepactive VLPO neurons onto histaminergic cells and other arousal centers drives and maintains sleep. Conversely, the wakepromoting centers turn off VLPO neurons directly (Gallopin et al., 2000; Chou et al., 2002) or indirectly via GABAergic interneurons (Liu et al., 2010). Accordingly, we found that photo-evoked release of histamine produces a feedforward inhibition of VLPO neurons, whereas in the TMN, histamine reduces GABAergic inputs onto histaminergic neurons. We propose that this inhibitory presynaptic effect of histamine on GABAergic afferents disinhibits TMN neurons, thereby promoting arousal.

These optogenetic experiments demonstrate synergistic mechanisms through which histamine may promote arousal by disinhibiting TMN neurons while inhibiting VLPO neurons. These results shed light on the cellular mechanisms through which histamine switches off VLPO neurons and perhaps their projections to TMN neurons, promoting high levels of vigilance and the maintenance of arousal.

\section{References}

Atasoy D, Betley JN, Su HH, Sternson SM (2012) Deconstruction of a neural circuit for hunger. Nature 488:172-177. CrossRef Medline

Brown RE, Stevens DR, Haas HL (2001) The physiology of brain histamine. Prog Neurobiol 63:637-672. CrossRef Medline

Chamberlin NL, Arrigoni E, Chou TC, Scammell TE, Greene RW, Saper CB (2003) Effects of adenosine on gabaergic synaptic inputs to identified ventrolateral preoptic neurons. Neuroscience 119:913-918. CrossRef Medline

Chotard C, Ouimet T, Morisset S, Sahm U, Schwartz JC, Trottier S (2002) Effects of histamine $\mathrm{H} 3$ receptor agonist and antagonist on histamine co-transmitter expression in rat brain. J Neural Transm 109:293-306. CrossRef Medline

Chou TC, Bjorkum AA, Gaus SE, Lu J, Scammell TE, Saper CB (2002) Afferents to the ventrolateral preoptic nucleus. J Neurosci 22:977-990. Medline

Chun S, Bayazitov IT, Blundon JA, Zakharenko SS (2013) Thalamocortical long-term potentiation becomes gated after the early critical period in the auditory cortex. J Neurosci 33:7345-7357. CrossRef Medline

Diester I, Kaufman MT, Mogri M, Pashaie R, Goo W, Yizhar O, Ramakrishnan C, Deisseroth K, Shenoy KV (2011) An optogenetic toolbox designed for primates. Nat Neurosci 14:387-397. CrossRef Medline

Franklin FBJ, Paxinos G (1997) The mouse brain in stereotaxic coordinates. San Diego: Academic.

Gallopin T, Fort P, Eggermann E, Cauli B, Luppi PH, Rossier J, Audinat E, Mühlethaler M, Serafin M (2000) Identification of sleep-promoting neurons in vitro. Nature 404:992-995. CrossRef Medline

Haas H, Panula P (2003) The role of histamine and the tuberomamillary nucleus in the nervous system. Nat Rev Neurosci 4:121-130. CrossRef Medline

Haas HL, Sergeeva OA, Selbach O (2008) Histamine in the nervous system. Physiol Rev 88:1183-1241. CrossRef Medline

Huang ZL, Qu WM, Li WD, Mochizuki T, Eguchi N, Watanabe T, Urade Y, Hayaishi O (2001) Arousal effect of orexin A depends on activation of the histaminergic system. Proc Natl Acad Sci U S A 98:9965-9970. CrossRef Medline

Jackson AC, Bean BP (2007) State-dependent enhancement of subthreshold A-type potassium current by 4-aminopyridine in tuberomammillary nucleus neurons. J Neurosci 27:10785-10796. CrossRef Medline

Kukko-Lukjanov TK, Panula P (2003) Subcellular distribution of histamine, GABA and galanin in tuberomamillary neurons in vitro. J Chem Neuroanat 25:279-292. CrossRef Medline

Lin JS, Sergeeva OA, Haas HL (2011) Histamine H3 receptors and sleepwake regulation. J Pharmacol Exp Ther 336:17-23. CrossRef Medline

Liu YW, Li J, Ye JH (2010) Histamine regulates activities of neurons in the ventrolateral preoptic nucleus. J Physiol 588:4103-4116. CrossRef Medline

Merickel A, Edwards RH (1995) Transport of histamine by vesicular monoamine transporter-2. Neuropharmacology 34:1543-1547. CrossRef Medline

Mochizuki T, Yamatodani A, Okakura K, Takemura M, Inagaki N, Wada H (1991) In vivo release of neuronal histamine in the hypothalamus of rats measured by microdialysis. Naunyn Schmiedebergs Arch Pharmacol 343: 190-195. CrossRef Medline

Mochizuki T, Arrigoni E, Marcus JN, Clark EL, Yamamoto M, Honer M, Borroni E, Lowell BB, Elmquist JK, Scammell TE (2011) Orexin receptor 2 expression in the posterior hypothalamus rescues sleepiness in narcoleptic mice. Proc Natl Acad Sci U S A 108:4471-4476. CrossRef Medline

Nelson LE, Guo TZ, Lu J, Saper CB, Franks NP, Maze M (2002) The sedative component of anesthesia is mediated by GABA(A) receptors in an endogenous sleep pathway. Nat Neurosci 5:979-984. CrossRef Medline

Nicholson AN, Pascoe PA, Stone BM (1985) Histaminergic systems and sleep: studies in man with $\mathrm{H} 1$ and $\mathrm{H} 2$ antagonists. Neuropharmacology 24:245-250. CrossRef Medline

Panula P, Pirvola U, Auvinen S, Airaksinen MS (1989) Histamineimmunoreactive nerve fibers in the rat brain. Neuroscience 28:585-610. CrossRef Medline

Parmentier R, Ohtsu H, Djebbara-Hannas Z, Valatx JL, Watanabe T, Lin JS (2002) Anatomical, physiological, and pharmacological characteristics of histidine decarboxylase knock-out mice: evidence for the role of brain histamine in behavioral and sleep-wake control. J Neurosci 22:76957711. Medline 
Saper CB, Fuller PM, Pedersen NP, Lu J, Scammell TE (2010) Sleep state switching. Neuron 68:1023-1042. CrossRef Medline

Sherin JE, Elmquist JK, Torrealba F, Saper CB (1998) Innervation of histaminergic tuberomammillary neurons by GABAergic and galaninergic neurons in the ventrolateral preoptic nucleus of the rat. J Neurosci 18: 4705-4721. Medline

Steininger TL, Gong H, McGinty D, Szymusiak R (2001) Subregional organization of preoptic area/anterior hypothalamic projections to arousalrelated monoaminergic cell groups. J Comp Neurol 429:638-653. CrossRef Medline

Takahashi K, Lin JS, Sakai K (2006) Neuronal activity of histaminergic tuberomammillary neurons during wake-sleep states in the mouse. J Neurosci 26:10292-10298. CrossRef Medline

Thakkar MM (2011) Histamine in the regulation of wakefulness. Sleep Med Rev 15:65-74. CrossRef Medline

Tritsch NX, Ding JB, Sabatini BL (2012) Dopaminergic neurons inhibit striatal output through non-canonical release of GABA. Nature 490:262-266. CrossRef Medline
Williams RH, Morton AJ, Burdakov D (2011) Paradoxical function of orexin/hypocretin circuits in a mouse model of Huntington's disease. Neurobiol Dis 42:438-445. CrossRef Medline

Yanovsky Y, Zigman JM, Kernder A, Bein A, Sakata I, Osborne-Lawrence S, Haas HL, Sergeeva OA (2012) Proton- and ammonium-sensing by histaminergic neurons controlling wakefulness. Front Syst Neurosci 6:23. CrossRef Medline

Zecharia AY, Nelson LE, Gent TC, Schumacher M, Jurd R, Rudolph U, Brickley SG, Maze M, Franks NP (2009) The involvement of hypothalamic sleep pathways in general anesthesia: testing the hypothesis using the GABAA receptor beta3N265M knock-in mouse. J Neurosci 29:21772187. CrossRef Medline

Zecharia AY, Yu X, Götz T, Ye Z, Carr DR, Wulff P, Bettler B, Vyssotski AL, Brickley SG, Franks NP, Wisden W (2012) GABAergic inhibition of histaminergic neurons regulates active waking but not the sleep-wake switch or propofol-induced loss of consciousness. J Neurosci 32:13062-13075. CrossRef Medline 